\title{
Rasgos estilísticos en algunas novelas de Eduardo Mallea
}

A obra de Eduardo Mallea ofrece una interprctación madura y seria 1 de la vida argentina en sus valores más hondos y permanentes. Sus novelas revelan una profunda preocupación por el progreso moral y social de su país, y a la vez una fe inquebrantable en cu porvenir. En este trabajo me limito a escribir sobre algunos aspectos de la técnica estilística de este autor, de su prosa como indicio personal de su atte.

Los elementos más esenciales y originales de la obra de Mallea giran alrededor de lo psicológico y lo intelectual. Su novela de ideas, de planteamiento de problemas, de conflictos personales y de búsquedas estériles, muestra una prosa que es en gran medida la expresión literaria de estados emocionales y de causas y motivos de conducta. Por encima de las des. cripciones del ambiente físico, del desarrollo de sucesos, o de escenas de acción, se destaca la pintura pormenorizada del mundo más íntimo, más hondo de los personajes. Este carácter de la prosa de Mallea, esta pasión por concebir el lenguaje en un plano de casi excesiva psicología, se revela a cada paso en párrafos como el siguiente, tomado de su novela Todo verdor perecerá:

Ella tuvo compasión por ese pobre hombre vencido. Tuvo que levantar su soledad de taíz frente a ese espectro que de ahí en adelante se sentó frente a ella a la mesa, más abrupto que nunca, que no hablaba, que no decía lo que pensaba ni lo que sentía. Como nunca había tenido hacia él amor, Âgata tuvo que hacer un esfuerzo sobrehumano para edificar una actitud en la que no cupiera una sombra de ella misma sino el reflejo de un cariño inventado. Pero, ¿cómo iba a llegar hasta el lastimado, si detrás del lasstimado estaba más vivo que nunça el otro, ese monstruo, el rẹsẹntido? 
Cuanto más pugnaba ella por vencer ese necesatio combate, más sentía cono en aquel otro cuerpo la amargura y el despecho estaban por explotar. ${ }^{1}$

En otros trozos de igual índole psicológica e introspectiva, el lenguaje posee cierto tono rebuscado, complicado, lleno de palabras y giros violentados más de lo que es razonable. De Los enemigos del alma sacamos este ejemplo, en que se hace notar el conflicto tremendo entre los tres hermanos Guillén debido a sus temperamentos opuestos y a la falta de entendimiento mutuo:

Cuando Débora estalló en la réplica gritando que el más grande juzgador era él, pues del agravio de sus juicios hacía gozo, complaciéndose en la justificación que para los cínicos implica el extravío de los demás, la caída general y la bajeza de todos, cuando le gritó que él pertenecía a la especie de los alegres atribuidores de ignominia, a aquellos en quienes la ajena corrupción florece en corolas de complacencia, en sarcasmos, en sonrisas cómplices, en fin en una frívola relajación de los resortes de soledad, las palabras se hicieron feroces y Cora abundó al fin con un grito para aplacar a aquellos contrarios pugnaces. ${ }^{2}$

Es precisamente en estas secciones de análisis interior en donde más se nota la prolijidad con que se reviste a veces su prosa. Tiene Mallea mucho que decir, pero abusa con demasiada frecuencia de la paciencia del lector y sacrifica el interés sostenido de la obra para sondear cada matiz de emoción y de pensamiento.

La prosa de Mallea revela ciertos toques de estilo, ciertas características en la selección y el empleo de palabras que constituyen una nota propia y saliente de su arte. Estos rasgos nos interesan ahora.

Las contradicciones de la vida, verdaderas o aparentes, las paradojas, y toda clase de yuxtaposición de conceptos, en las cuales encuentra Mallea tanta sustancia filosófica, se incorporan repetidas veces en su lenguaje en diversas formas. El novelista juega ingeniosamente con una idea cuando dice, por ejemplo: "Todo lo estático es desorden; en cambio, el desorden mismo - la gente que camina, las luces efímeras, pero intensas...- asume la categoría de un orden, pues es 1itmo". "También esta frase: "A nadie se odia como a aquél que obtiene de nosotros para su gozo la co-

1 Eduardo Mallea, Todo verdor perecerá (Buenos Aires: Espasa-Calpe, 1941), págs. 83-84. El párrafo se refiere a la tirantez y al descontento emocionales de Ágata Cruz, mujer inestable y hostil, casada con un hombre adusto, agrio y silencioso.

2 Eduatdo Mallea, Los enemigos del alma (Buenos Aires: Editorial Sudamericana, 1950), p. 78 .

3 Eduardo Mallea, La babia de silencio (Buenos Aires: Editorial Sudameriçana, 1940), págs. 177-178: 
media de nuestra tragedia". 4 En otros casos la contradicción se hace más enfática y extraña cuando las palabras opuestas se colocan en muy estrecha proximidad y la una es una forma negativa de la otra:

...el escenario... lleno de desconocidos conocidos. ${ }^{5}$

...mueren al fin en el caldo de su propia insuficiente suficiencia. ${ }^{6}$

...ignoraban que lo que hacía era dar ocupación a la desocupación. ${ }^{7}$

Era una espera, la paciencia de una impaciencia. ${ }^{8}$

...olor a deshabitación habitante. ${ }^{9}$

La negación puede ser también un vocablo aparte:

...mirando $\sin$ mirar. . ${ }^{10}$

... porque son las no ficticias ficciones. ${ }^{11}$

...algo preocupaba ahora a la no preocupada. ${ }^{12}$

En muchos casos la posición cercana de palabras opuestas sirve principalmente de contraste, en que la semejanza de formas hace que el lector se detenga un poco para captar el concepto semántico:

... en sus confesiones casi inconfesables. ${ }^{13}$

... se resistió a fomentar con su cuidado tanto descuido. ${ }^{14}$

Era curioso que aquella tregua, aquella reserva, se pareciera a un respeto profesado a lo irrespetable. ${ }^{10}$

Era... la espera imprecisa de algo preciso. ${ }^{16}$

... debemos vivirlo en proporciones calculadamente incalculables. ${ }^{17}$

La revolución francesa... señaló por primera vez la infalibilidad de la instancia más falible del mundo. ${ }^{18}$

4 Los enemigos del alma, p. 277. De aquí en adelante incluyo en este trabajo un número de citas tal yez excesivo. Pero creo que sirve un fin valioso-el de apuntar concretamente ciertos rasgos peculiares del estilo de Mallea. Las citas aquí presentadas no son ejemplos aislados, ni son casos de poca frecuencia, seleccionados por su carácter raro dentro de la obra del autor. Más bien, son representativas de otras muchas que con igual provecho se pudieron haber empleado. p. 497.

5 Eduardo Mallea, Simbad (Buenos Aires: Editorial Sudamericana, 1957),

6 La babia de silencio, p. 197.

7 Los enemigos del alma, p. 29.

8 Ibid., D. 308. p. 17 .

- Eduardo Mallea, La torre (Buenos Aires: Editotial Sudamericana, 1950),

io Simbad, p. 16.

11 Ibid., p. 277.

12 La torre, p. 362.

13 Simbad, D. 202.

14 Los enemigos del alma, p. 74.

15 Ibid., p. 208.

16 Ibid., p. 294.

17 Ibid., D. 301.

18 La babia de silencio, p. 152. 
La repetición en el lenguaje ocupa un lugar bien evidente e importante en toda la obra de Mallea. Esta técnica estilística, que usa Mallea tal vez un poco más de lo mesurado, asume una gran variedad de formas dentro del propósito fundamental de intensificar, cle hacer hincapié en una palabra o en una oración entera. Como recurso empleado con moderación, la repetición se encuentra comúnmente en muchos autores. El lector la acepta como una técnica eficaz que ocurre de cuando en cuando, y no la considera con interés especial. Pero Mallea excede todos los límites, tanto por el gran número de repeticiones como por la naturaleza extravagante de muchas de ellas.

De la simple repetición de una palabra, ya sea adjetivo, adverbio, sustantivo u otra parte de la oración, no es preciso hacer mención especifica por ser demasiado obvia. De ello pasamos a formas más excepcionales y exageradas, como la repetición triple o cuádruple de la misma voz dentro de una frase:

.. las noches antes, la tarde antes, la noche antes. ${ }^{19}$

...cruzó una idea fulgurante, una idea mordiente, una idea desnuda. . . ${ }^{20}$

Mas no el mundo mundo, el mundo de los otros, el mundo exterior y sensible..., sino un raro mundo circuído y abrazado por él. ${ }^{21}$

Muchas veces la palabra se repite dentro de una estructura violentada y estrambótica, ya para señalar un matiz deseado, ya para usar la voz como elemento temático de la oración. Tomemos por ejemplo esta frase: "No les tenía temor ni no temor; le eran ajenos". ${ }^{22}$ Es evidente aquí que Mallea busca la repetición de la voz "temor", aunque así tuerce la forma sintáctica. Otros casos siguen:

Su infancia solitaria, su no infancia... ${ }^{23}$

...la prueba definitiva de mi desesperación, la desesperación de mi desesperación. ${ }^{24}$

Y la boca se le sonreía no de incredulidad, sino de la incredulidad. ${ }^{25}$ .. había menos sinceridad que orgullo de sinceridad. ${ }^{26}$

19 La torre, D. 402.

20 Ibid., p. 369.

21 Los enemigos del alma, p. 265. Podemos agregar que en una ocasión Mallea repite la voz "familiar" "diez veces en la misma frase, haciendo que modifique una serie de sustantivos. En Fiesta en noviembre (Buenos Aires: Editorial Losada, 1942), p. 45.

22 Los enemigos del alma, p. 293.

23 Todo verdor perecerá, p. 27.

24 La babia de silencio, p. 370.

25 Los enemigos del alma, p. 141 ,

36 lbid., p. 127. 
...pero Dios hizo a los insistentes insistentes. ${ }^{27}$

¿Eran menos que hombres? No. Eran hombres. Se habían reducido sólo a eso. Se habían reducido sólo al eso de eso. ${ }^{28}$

...pero ella era como la infancia de la infancia que ya no podemos vulnerar-el dolor del dolor. ${ }^{29}$

Era una bailarina para él, of reciéndole todo el espectáculo de su espectáculo. ${ }^{30}$

Era todavía la idea de la idea. ${ }^{31}$

El él de él era el ingresado en un mundo que... ${ }^{32}$

Se da el caso también en que se repite un grupo entero de palabras, a veces con una pequeña modificación:

Al día siguiente del día siguiente llamó por teléfono... ${ }^{33}$

...pero la conciencia desconfiada de él era más rápida, porque era la des. confiada conciencia de un artista. ${ }^{34}$

Habría querido estimularlo, habría querido poder estimularlo. ${ }^{35}$

Asimismo, se extiende la repetición a una serie de oraciones o a un párrafo completo, en que una palabra, o un grupo de palabras, forma el hilo de continuidad:

Porque le importaba. Le importaba más que cualquier otra cosa en el mundo. Era la única cosa en el mundo que le importaba. ${ }^{36}$

Bajaba como esta vez: lenta, laxa, envuelta en un batón de seda. . . unos ojos negros, muy profundos, lentos. Todo en ella era lento. ${ }^{37}$

Técnica que va estrechamente unida a la de la repetición exacta de palabras es el empleo de distintas formas verbales procedentes de la misma raíz etimológica. Esto se hace con marcada intención estilística, pero al mismo tiempo con un propósito de sugestión emocional. De manera que el autor hace una agrupación alrededor de la raíz tem-, en la cual aparecen en la misma oración las formas afines temblando, temor, y tembloro. so; o alrededor de ferr-, berr-, dando bierro y berrumbroso. Citamos abajo varias otras locuciones para notar cómo se manifiesta esta técnica en diversas formas:

27 Ibid., 5. 300.

28 Simbad, p. 734.

29 Ibid., p. 741.

so Ibid., p. 18.

31 Ibid., p. 345.

32 Ibid., p. 418.

33 Ibid., p. 419.

34 Ibid., p. 498.

35 Todo verdor pereceri, p. 14.

36 Los enemigos del alma, p. 17.

97 Ibid., p. 24. 
...cuyo vestido verde loro probaba a todo probar su desinterés sin remedio. ${ }^{38}$

Ella apoyaba a todo apoyar... ${ }^{39}$

El viejo librero, encorvado de tanto encorvarse. . .40

...y que vivieron sumariamente como entes liquidados que liquidan. ${ }^{41}$

$\ldots$ vehementes de vehemencia, bruscos de brusquedad. ${ }^{2}$

...perseguido por su persecución... ${ }^{43}$

...pero uno demora todo lo demorable. ${ }^{44}$

$\mathrm{Y}$ también obsérvense los casos siguientes, donde Mallea emplea la construcción del acusativo iterativo, en que se repite en el complemento lo que se ha expresado ya en el verbo:

...almorzaron los tres habitantes el almuerzo.45

... sorprendiendo su sorpresa. ${ }^{46}$

...alguien a quien ilusionara su ilusión. ${ }^{47}$

Las dos palabras de la misma raíz pueden hallarse en posición contigua, dando un conjunto de voces muy raro:

Era la fácil facilidad del comienzo...48

...muchachas agitadas por una inquietante inquietud...49

...la arquitectura... hecha de horrible e imprevisora imprevisión.50

... literatura que nace de una razón razonante... ${ }^{51}$

... su fastidiante fastidio... ${ }^{52}$

¡Cuánto le gustaba gustar!53

Mallea coloca también en estrecha proximidad dos vocablos de la misma raíz de significado distinto, aunque emparentado:

38 La torre, p. 137.

39 Ibid., p. 224.

40 Ibid., p. 232.

41 Ibid., p. 348.

42 La babia de silencio, p. 421.

43 Simbad, p. 695.

44 Los enemigos del alma, p. 127.

45 Ibid., p. 24.

46 Simbad, p. 86.

47 Ibid., p. 422.

48 Ibid., p. 558.

49 Fiesta en noviembre, p. 44.

50 La babia de silencio, p. 178.

51 Ibid., p. 300.

52 Los enemigos del alma, p. 101.

53 Ibid., p. 265. 
$\therefore$ como auditorio ignorado e ignorante. ${ }^{54}$

... impaciente e impacientante...55

... sólo poder, poderío. . .56

Estaba habituada a verlo fastidiado, fastidioso... ${ }^{57}$

Las primeras palabras individuales, individualizables... ${ }^{58}$

De igual modo Mallea emplea en la misma cración dos vocablos que se asemejan por la apariencia o por el sonido, pero no son necesariamente de la misma raíz o de sentido afín. Aquí puede observarse claramente la gran ingeniosidad verbal del autor, que parece deleitarse en manejar un poco caprichosamente el rico mundo de las palabras:

... intuía la belleza como una instancia estable, extática y estática... ${ }^{59}$

Mientras atravesaba hacia la plaza aniquilada por la siesta, cegada y segada del todo de sol. . . ${ }^{60}$

Y ella, embargada, embriagada en las ondas de aquel orgullo... ${ }^{61}$

... se empeñaba por desempeñar con eficacia el papel... . ${ }^{62}$

Estaba acosada y acotada. ${ }^{63}$

Y la figura orante, implorante...64

Godo no tenía ciencia ni conciencia sino de lo que le servia para difamar. ${ }^{65}$

Junto con la repetición exacta y el empleo de voces emparentadas se halla el recurso de amontonar palabras, giros y cláusulas que llevan entre sí una semejanza de sentido. Así, la oración o el párrafo se extiende, se ensancha, a medida que Mallea acumula con completa libertad estas expresiones similares, con el fin de fijar o aclarar mejor el pensamiento, la emoción, o la descripción que él procura transmitir al lector. Es evidente la preocupación de Mallea por la exacta reproducción escrita de lo que piensa y siente. Cuando no le sirve cabalmente una sola expresión para lograr este fin, se vale de un grupo de giros que en su conjunto va aproximándose al significado deseado:

54 Ibid., pp. 130-131.

55 Ibid., p. 118.

56 Ibid., p. 159.

57 Simbad, p. 498.

58 Ibid., p. 456.

59 Ibid., p. 70.

60 Lat torre, p. 57.

61 Ibid., p. 203.

62 Ibid., p. 204.

63 Los enemigos del alma, p. 296.

64 Ibid., p. 139.

65 Ibid., p. 49. 

bra... ${ }^{66}$

Sólo de tiempo en tiempo debía consentir, asentir, contestar una pala... y renegó a su hermana, la suya propia, la de él. ${ }^{67}$

Era peor que un dolor...: algo que se resistía a disiparse, a desatarse, a desaparecer. ${ }^{68}$ traño. 69

No le gustaba su fama. Era el no-él de él, lo otto, lo externo y ex...y esa mirada era una historia, la historia de él, la historia de él con ella, la historia de los dos.70

La tendencia de amplificar las frases, y hasta a veces de recargarlas, se revela también en el acopio sucesivo de un gran número de partes subordinadas, accesorias, dentro de la oración. Adjuntas al verbo principal están frases adverbiales, adjetivales, preposicionales, así como cláusulas interpoladas, produciendo el efecto de brazos que surgen del cuerpo de la oración:

Debajo del mismo daguerrotipo, cada tarde, la madre, en octubre, al borde de la ventana del dormitorio, con una voz en cuya fatigada monotonía hallaba la niña el encanto, leía a Consuelo esos pasajes de las Escrituras que la hija retenía sin entender tampoco, ligera por vacar a sus juegos. ${ }^{71}$

La llevó, la empujó casi, hasta aquel rincón, detrás del piano, entre el piano y la pared, bajo el retrato solemne del viejo don León..$^{72}$

Con el diario delante, en la biblioteca, a la mañana siguiente, se estaba desayunando con café con leche y tostadas... ${ }^{73}$

Los elementos de su técnica aquí señalados dan indicación del carácter original de la prosa de Mallea. Siempre libre en su expresión literaria, muchas veces atrevido, no se deja conducir servilmente por una constante meta estética, ni por formas de léxico estrictamente tradicionales, ni por otras consideraciones artísticas que puedan restringir su pluma. No tolera freno artificial, y por eso no huye de la reiteración, ni de otros excesos estilísticos que puedan servirle. No permite que su mundo de palabras sea menos que su mundo de ideas y de emociones, y por esta razón no vacila en sacrificar, si es necesario, la belleza fría, la construcción bien ordenada y nítida, por una prosa viva y sensible, por un lenguaje que

66 Ibid., p. 166.

67 Ibid., p. 63.

68 Ibid., p. 359.

69 Simbad, p. 473.

70 Ibid., p. 743.

i1 Los enemigos del alma, p. 115.

72 La torre, p. 369.

73 lbid., p. 154 . 
comunica debidamente sus pensamientos. La prosa de Mallea obedece más a sus anhelos interiores que buscan expresión literaria, que a formas y disciplinas impuestas de afuera. Su lenguaje depara una nota fresca e independiente a la ficción argentina contemporánea.

Myron I. LichtBlaU,

Universidad de Indiana.

Bloomington, Indiana. 
